\title{
Dendrites equip neurons with a range of resonant frequencies
}

\author{
Jonathan Laudanski ${ }^{1 \dagger}$, Benjamin Torben-Nielsen ${ }^{2,3^{*}}$, Idan Segev ${ }^{3}$, Shihab Shamma ${ }^{4}$ \\ From Twenty First Annual Computational Neuroscience Meeting: CNS*2012 \\ Decatur, GA, USA. 21-26 July 2012
}

Resonance describes the ability of neurons to respond selectively to inputs at preferred frequencies [1]. When measured at the soma, neurons typically have one dominating resonant frequency to which they respond stronger than to other frequencies. A variety of ionic mechanisms support resonance and oscillation in neurons; the majority of these channels reside in the dendritic membrane. Here we analyzed the impact of lowthreshold potassium current (KLVA) in dendrites, utilizing two approaches to gain insights into the role of dendrites in neuronal resonance.

First, an analytical approach was used whereby the $\mathrm{K}_{\mathrm{LVA}}$ voltage-dependence was linearized and the transfer impedance of in model consisting of a soma coupled to a cylindrical cable was derived analytically for each location along the dendrite. Changing the total density of $\mathrm{K}_{\mathrm{LVA}}$, gave rise to different resonant frequencies along the dendrite. This enables us to identify the membrane features that influence the range of resonances along the dendrites to characterize the trade-off between the range of frequencies and the Q-factor (i.e., the "strength" of a resonance frequency).

Second, we used a numerical approach to optimize dendritic features to create neuron models with a large range of resonant frequencies along their dendrites. We thus confirmed the analytical results and addressed the more complicated dendritic structures including branching. We found that dendritic branches (bifrucations) may increase the range of resonant frequencies in dendrites and, at least partially, may overcome the strong trade-off between resonant strength and the possible range of resonance frequencies found it unbranched structures.

\footnotetext{
* Correspondence: btorbennielsen@gmail.com

+ Contributed equally

${ }^{2}$ Edmund and Lily Safra Center for Brain Sciences, Hebrew University, Jerusalem, Israel

Full list of author information is available at the end of the article
}

We argue that the computational complexity of neurons is increased significantly by dendrites endowed with a whole range of resonant frequencies and discuss the advantage of having a bank of differential dendritic resonances that act as dynamic filters which, following plastic processes enable neurons to resonate in a particular desirable frequencies.

\section{Acknowledgements}

This research is partially supported by a FP7 People Initial Training Network Grant, Grant number: PITN-GA-2009-238686 (CEREBNET).

\section{Author details}

'Equipe Audition, Departement d'Etude Cognitive, Ecole Normale Superieure, Paris, France. ${ }^{2}$ Edmund and Lily Safra Center for Brain Sciences, Hebrew University, Jerusalem, Israel. ${ }^{3}$ Department of Neurobiology, Hebrew University, Jerusalem, Israel. ${ }^{4}$ Department of Electrical \& Computer engineering, University of Maryland, USA.

Published: 16 July 2012

\section{Reference}

1. Hutcheon $B$, Yarom $Y$ : Resonance, oscillation and the intrinsic frequency preferences of neurons. Trends in Neurosciences 2000, 23:216-222.

doi:10.1186/1471-2202-13-S1-P46

Cite this article as: Laudanski et al.: Dendrites equip neurons with a range of resonant frequencies. BMC Neuroscience 2012 13(Suppl 1):P46.

Submit your next manuscript to BioMed Central and take full advantage of:

- Convenient online submission

- Thorough peer review

- No space constraints or color figure charges

- Immediate publication on acceptance

- Inclusion in PubMed, CAS, Scopus and Google Scholar

- Research which is freely available for redistribution
C Biomed Central

C 2012 Laudanski et al; licensee BioMed Central Ltd. This is an Open Access article distributed under the terms of the Creative Commons Attribution License (http://creativecommons.org/licenses/by/2.0), which permits unrestricted use, distribution, and reproduction in any medium, provided the original work is properly cited. 